\title{
Patterns of mtDNA diversity in North Atlantic populations of the mussel Mytilus edulis
}

\author{
Cynthia Riginos $\cdot$ Christine M. Henzler
}

Published online: 2 September 2009

(C) Springer-Verlag 2009

\section{Erratum to: Mar Biol (2008) 155:399-412 DOI 10.1007/s00227-008-1038-4}

The post-colonization direction of gene flow in Fig. 5 was reversed. Although this mistake alters some conclusions regarding post-colonization gene flow (p. 405), IM-derived estimates of population splitting $(s)$ and divergence times are correct as reported and these data form the basis for the major conclusions regarding routes of colonization. The recombinant haplotype from Mahone NS is 677 not 667.

The online version of the original article can be found under doi:10.1007/s00227-008-1038-4.

\section{Riginos ( $\square)$}

School of Integrative Biology, University of Queensland,

St Lucia, QLD 4072, Australia

e-mail: C.Riginos@uq.edu.au

C. Riginos · C. M. Henzler

Department of Biology, Duke University,

Box 90338, Durham, NC 27708, USA

\section{M. Henzler}

Marine Science Institute, University of California Santa Barbara,

Santa Barbara, CA 93106, USA

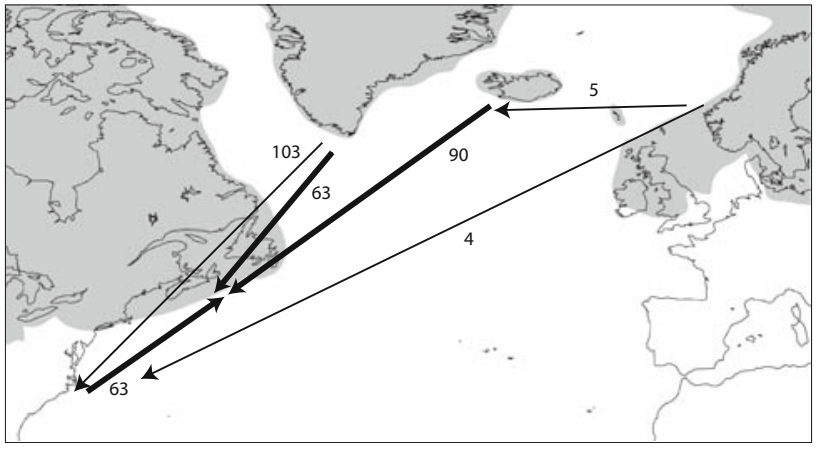

Fig. 5 Post-colonization gene flow. Arrows show all cases where the highest posterior probability of migration was greater than 0 (in models that included migration). Bold arrows show the instances where these probabilities were statistically significant $(P<0.05)$. Numbers are the point estimates of the number of migrants ( $\mathrm{Nm}$ or gene flow) per generation 